\title{
Exploration and Practice of Cross - border Electronic Commerce through Portable Quick Charging Products
}

\author{
Jinhao $\mathrm{Li}^{\mathrm{a}}$ and Jing Wang ${ }^{\mathrm{b}}$ \\ Neusoft Institute Guangdong, Foshan, Guangdong Province, China 528200 \\ a ljhgary@qq.com, bjingyun_wj@163.com
}

Keywords: Cross-border E-commerce;Portable Quick Charging; Entrepreneurship and Innovation

\begin{abstract}
Cross-border e-commerce is in the "golden age" in China. The "One Belt and One Road" initiative provides policy support to develop cross-border e-commerce. We explore and practice cross - border e-commerce transactions based on portable quick charging products developed by ourselves. Our products are portable, fast charging and good compatibility, which have obtained certain sales market in Indonesia. At last, we summarize the experiences, and propose the strategy that Cross-border E-commerce Enterprises Apply to Implement Brand Marketing.
\end{abstract}

\section{Current Situation and Development Trend of Cross-border E-commerce}

In recent years, with the rapid development of Internet technology and the promotion of economic globalization, e-commerce plays a more and more important role in international trade.. Compared with a long process of traditional commerce, the e-commerce is more dominant and is characterized by the globalization, intangibility, anonymity and instantaneity, thus greatly simplifying steps of trading and bringing infinite commercial opportunities for many enterprises.

The cross-border e-commerce, as the technical basis of promoting economic integration and trade globalization, has a very important strategic significance. The cross-border e-commerce not only breaks through the barriers between countries to make the international trade enter the borderless trade, but also causes great changes in the world economy and trade[1] . For enterprises, the open, multi-dimensional, three-dimensional multilateral economic and trade cooperation mode built by the cross-border e-commerce has greatly widened the path of entering the international market, and greatly promoted the optimizing configuration of multilateral resources and mutual benefit and win-win result between enterprises._For consumers, the cross-border e-commerce makes them easier to obtain information of other countries and buy cheap and fine goods.

Although cross-border e-commerce of China starts relatively late, but cross-border e-commerce has brought significant economic benefits for China's foreign trade enterprises and become irreplaceable component of national economy. The total volume of Chinese import and export trade was up to RMB 25.8 trillion in 2013. According to the year-on-year trend, it is estimated that the total volume will reach RMB 27.1 trillion this year, and the trade volume of cross-border e-commerce will rise from $12 \%$ to $14.76 \%$ [2]. China now is in the "Golden Age" of developing cross-border e-commerce, and the government has issued relevant policies to support it.Therefore, the cross-border e-commerce can go further away and continue to provide support for Chinese economic development, as long as the major e-commerce enterprises continuously conduct a deeper exploration in the payment process, logistics service, promotion platform and other professional aspects. The objective of this paper is to explore and practice cross - border e-commerce transactions based on portable quick charging products developed by ourselves.

\section{Introduction of Augus Quick Charger}

There are three obvious flaws in ordinary phone chargers. First, it needs the power supply. Second, charging time is too long, and it takes at least 3 hours to fill the phones. Third, the phone 
charger can only charge this kind of mobile phones, and it can't be compatible with other brands. Portable power source, which integrate the power supply and charging function, can charge mobile phones and other digital equipment anytime and anywhere. However, this charging product still doesn't solve the two problems:long charging time and worse compatibility. Now, quick charging technology is developed, which improves the transmission power by increasing the voltage or current. Based on the quick charging technology, our team develops a portable quick charging product named Augus bidirectional quick charger, shown as Figure1. After the sequential evaluation, when the mobile devices use Augus bidirectional quick charger on the premise that the battery charge-discharge frequency is not reduced, the efficiency is 33\% , faster than the existing portable power source in the market. Moreover Augus quick charging technology can effectively improve charging speed as high as $27 \%$, and reduce power loss as high as $45 \%$. On the other hand, Augus quick charger can automatically identify the charging voltage of multiple equipment though the multi-range voltage, which will be a breakthrough in the battery industry and a large milestone in the charging industry. The experimental results are illustrated in the table1 and table 2 [3].

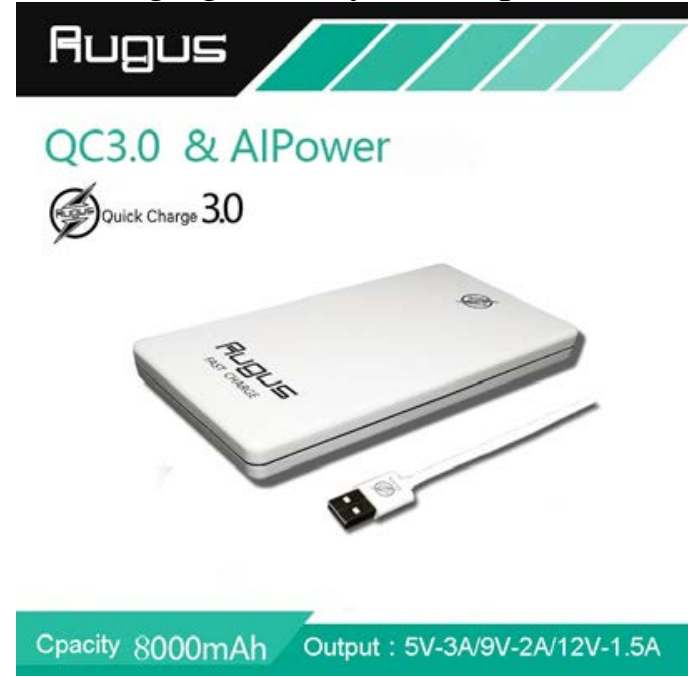

Fig1. Augus Bidirectional Quick Charger

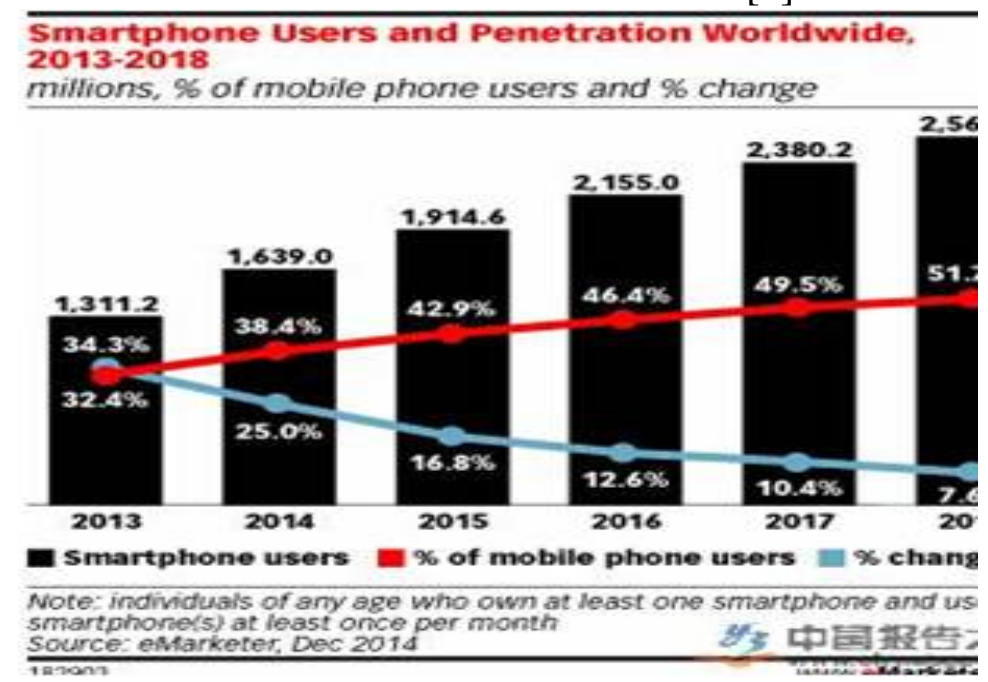

Fig 2.Smartphone Users and Penetration Worldwide 2013-2018

So our products can quickly and safely provide a full charge for the electronic charge through the use of the quick charging technology, and charging rate is no less than the traditional voltage Charging effect, safety and reliability are the sole premise of this product.

It is predicted that, the global Smartphone users will be more than 2.5 billion people by 2018 , and the compound growth rate will reach 14.3\% from 2013 to 2018 [4], shown as Figure 2. The global Smartphone users steadily increase and more users select the portable quick charging products. Thus, this kind of quick charging products can bring more and greater economic benefits for enterprises.Our Augus Qucik Charger has more competitive in the market, and we also hope to find a new sales channel for the product through the practice of cross-border e-commerce.

Table 1. Laboratory Evaluation Data of Augus Quick Charger

\begin{tabular}{|c|c|c|c|}
\hline $\begin{array}{c}\text { The time of } \\
\text { filling phone }\end{array}$ & $\begin{array}{c}\text { XiaoMi Mobile } \\
\text { Power } \\
\text { NDY-02-AL }\end{array}$ & $\begin{array}{c}\text { Augus bidirectional Quick } \\
\text { Charge Mobile PowerAugus 1 }\end{array}$ & $\begin{array}{c}\text { Efficiency } \\
\text { ratio }\end{array}$ \\
\hline $\begin{array}{c}\text { SamSung } \\
\text { Galaxy S7 edge } \\
(3600 \text { mah })\end{array}$ & $\begin{array}{c}13093 \text { seconds } \\
\text { Equal 3 hours 38 } \\
\text { minutes } 13 \text { seconds }\end{array}$ & $\begin{array}{c}4415 \text { seconds } \\
\text { Equal 1 hour 13 minutes 35 } \\
\text { seconds }\end{array}$ & $296.56 \%$ \\
\hline $\begin{array}{c}\text { Apple iPhone } \\
6 \text { s Plus }\end{array}$ & $\begin{array}{c}9428 \text { seconds } \\
\text { Equal 2 hours 37 } \\
\text { minutes 08 seconds }\end{array}$ & $\begin{array}{c}\text { 5914 seconds } \\
\text { Equal 1 hour 38 minutes 34 } \\
\text { seconds }\end{array}$ & $159.4 \%$ \\
\hline
\end{tabular}


Table 2. Laboratory Evaluation Data of Augus Qucik Charger

\begin{tabular}{|c|c|c|c|}
\hline & $\begin{array}{c}\text { XiaoMi Mobile } \\
\text { Power } \\
\text { NDY-02-AL }\end{array}$ & $\begin{array}{c}\text { Augus bidirectional } \\
\text { Quick Charge Mobile } \\
\text { Power Augus 1 }\end{array}$ & Efficiency ratio \\
\hline $\begin{array}{c}\text { Full of mobile } \\
\text { power 8000 mAh } \\
\text { time }\end{array}$ & $\begin{array}{c}8 \text { hours and 39 } \\
\text { minutes }\end{array}$ & 4 hours and 46 minutes & $181.47 \%$ \\
\hline
\end{tabular}

\section{Exploration and Practice of Entrepreneurship}

\subsection{The “One Belt and One Road” Initiative Provides Policy Support}

With the "One Belt and One Road" Initiative as the focus of all circles, a series of preferential and support policies have been issued successively in the corresponding fields. In order to make the cross-border e-commerce become a new growth point of China's economic development, related departments and local governments of the central government have introduced preferential policies to encourage the development of cross-border e-commerce.

At present, China's cross-border e-commerce market is mainly distributed in developed countries like United States, Britain, Germany and France and so on. Meanwhile, with constant appearance of emerging markets, other countries like Russia, Brazil, India etc., have becoming emerging markets for China's cross-border e-commerce as these countries have strong demand although they are undeveloped. However, China-made products are attractive in price and quality, China could enjoy quite a great competitiveness in these emerging markets abovementioned[4]. In addition, Asia's peripheral markets such as the Southeast Asian market is also a region with large market potential due to its relatively weak domestic manufacturing industry; Other regions with undeveloped e-commerce like Central and Eastern Europe, Latin America, Africa, etc., will also be growth points for China's cross-border e-commerce market in the future.

However, in practice, it should be emphasized that the regional economic development of the "One Belt and One Road” is generally lagging behind, so it needs to meet regional requirements to develop cross-border e-commerce rather than indiscriminately imitate the international 65 cross-border e-commerce paradigm. It means that these regions need to have their own innovative ideas to develop cross-border e-commerce. However, as some issues like customs clearance, logistics, payment platform security, disclosure of users' information, etc., have become a bottleneck that restricts the development of cross-border e-commerce, it has conformed to current industrial transformation and upgrading as well development needs of market economy to explore the development model of cross-border e-commerce in the "One Belt and One Road" strategic regions. At present, China's factor-driven strategy has transformed into innovation-driven development strategy, so each industry must actively explore the innovative development strategy and the cross-border e-commerce within the "One Belt and One Road" strategic regions also has to innovate its development model.

\subsection{Product Quality is the First Basis}

In the process of establishing products for the Indonesian market, at first we thought that the Indonesian consumption level is not high, so we just introduced low price products. However, the sales volume has declined two or three months after the low-price strategy bonus period and the cross-border sales fell into a predicament. Subsequently, we visited local wholesale manufacturers and large retailers. By carefully discussing about local crowds of low consumption ability and repeat market survey, shown as Figure 3, we found that when selecting products, the first thing they keep in mind was still quality regardless price of products.

Subsequently, according to such market characteristics, we precisely invested in a small amount 
of online video advertising through local video media to build brand quality and test product sales results. The product brand was exposed within local small areas and product sales volume saw a slight rise, but it was far from introducing and popularizing brand. In the next moment, by negotiating with source manufacturers, we replaced appearance material of products, product internal lines, improved product quality and upgraded product lines. After upgrade, the sales volume of products was recovered to original height once again, seen as Figure 4, with the help of brand advertising. Obviously, low-price sales can enable products to quickly step into one market at earlier time and earn part of profits. Whereas, from the point of view of long-term business, it's fundamental of long-term development for cross-border e-commerce to give up the price strategy, pay attention to improve product quality, establish a stable customer base, provide a good sales service and strive to build a product quality assurance system.

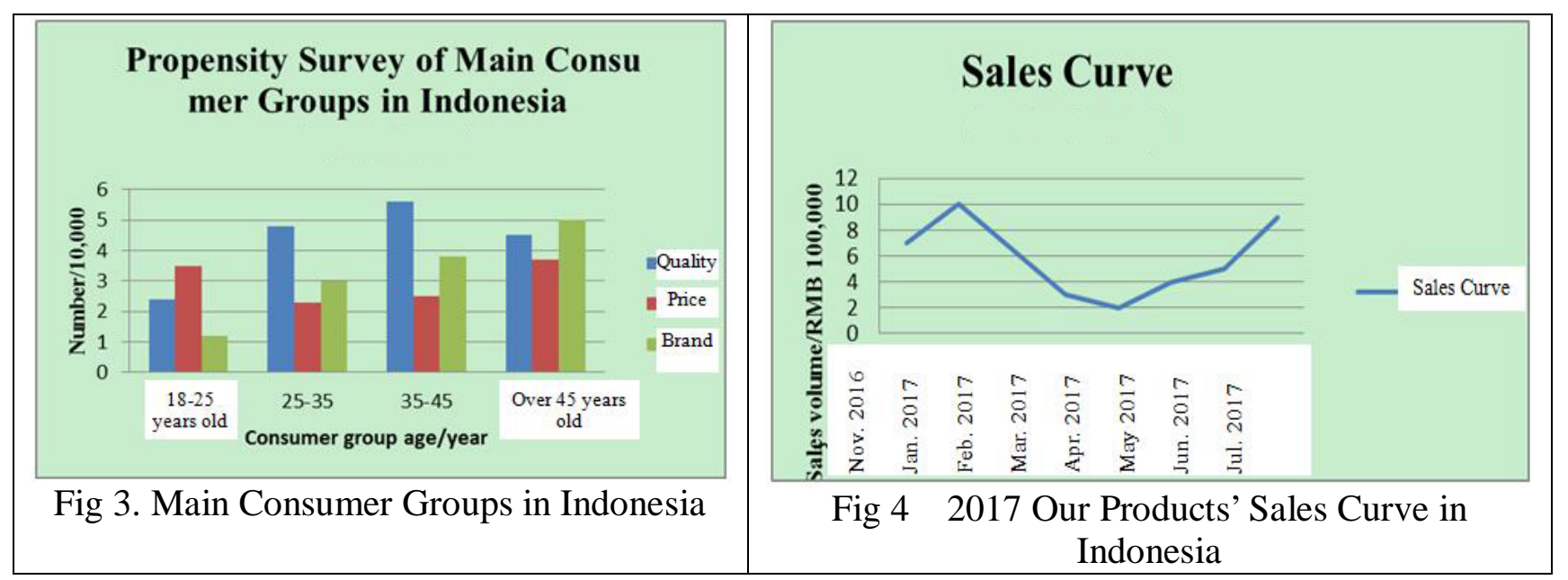

\subsection{The Strategy that Cross-border E-commerce Enterprises Apply to Implement Brand Marketing.}

\subsubsection{To create a good cross-border e-commerce service team to enhance the brand marketing capability}

A full-featured e-commerce team should have comprehensive capacities, like platform operation, product development, marketing tools, logistics options, customer service[6]. At present, many cross-border e-commerce teams have strong abilities in platform operation, while relatively weak in brand marketing, overseas sales channels, after-sales service, etc. Therefore, the e-commerce teams could enhance their own capabilities in brand marketing through training, e-commerce exchanges and learning from the practice of foreign e-commerce. The cross-border e-commerce should implement the brand marketing from this own actual situation. Firstly, register in the target countries and regions that main consumption crowds locate and then combine online marketing and offline brand building by its own team. When the online marketing develops to a reputation with certain basis, implement market segmentation in the major foreign markets and introduce foreign local e-commerce for cooperation to localize the brand. Then, implement brand distribution strategy and even the global distribution strategy in major countries and regions. Gradually develop to subsequent B2B2C mode from B2C.

3.3.2 Do a good job of products and services, choose the good e-commerce platform or develop their own e-commerce platform.

Compared with the traditional foreign trade, the procurement characteristics of the overseas buyers are more times, less quantity and short delivery time. Every detail involved in the product quality and service can be quickly experienced \& perceived and feedback on the e-commerce platform. These cumulative feedback word-of-mouths are related to the subsequent sales of cross-border e-commerce. Therefore, the cross-border e-commerce enterprise should pay attention to the following points. First, when choosing other e-commerce platforms to open stores or 
developing their own platforms, it is important to adhere to the principle of the priority of the buyer. Their own brand reputation shall be quickly formed through the sales. Moreover, we can learn from Amazon's practice of adhering to the customer centered values, leaving their purchase experience on the product sales page, forming a word of mouth. Second, we should focus on the platform of professional management of brand products, to avoid different categories of products together to form a hodgepodge. Whether in Amazon and E-Bay open cross-border stores, or enterprises open B2C site, in the management of brand products, should be professional, rather than hypermarkets promotions.

\subsubsection{Choose flexible and smooth logistics company and perfect payment system}

The cross-border e-commerce should choose the flexible and smooth logistics company to deliver the goods to the buyer in the most efficient manner in accordance with the operated brand products and the distribution characteristics of the overseas buyers.In the premise of sales profits, FEDEX, UPS, DHL, TNT and other international famous express delivery companies should be chosen. Not only can the buyers receive the purchased goods quickly, but also experience the strength and brand services of cross-border e-commerce through the adoption of these well-known express delivery companies.For the relatively large number of goods and not so urgent receiving time of the customer, the cross-border can ask Maersk and other international shipping companies to transport.However, for small parcels, the expensive international courier fee that the value of the sold goods is difficult to pay for and the urgent receiving time of the customer, the cross-border can adopt the "PayPal Package" jointly launched by Pay Pal and Beijing Post, "SFbuy" of S.F., "EAEMALL" of China Eastern Airlines and other logistics distribution modes.These delivery methods can not only meet the requirements (e.g. cost and delivery time) of sellers, but also the seller and buyer can query the operation status of the package in real time. In addition, in terms of the payment, the credit cards, bank transfer, third-party payment and other payment methods can be adopted to meet the payment requirements of different buyers in the premise of ensuring the safety of the collection.he payment method, with many types of currency, that is widely used by users shall be chosen, such as the largest and most advanced electronic exchange. For example, Western Union is Paypal which has 132 million users, and can support 25 kinds of currency payment transactions.

\section{Conclusion}

With the development of trade globalization, there are the continued opportunities in global sales market, but the pressure of the competition is still not a few. In the process of product sales, it is inevitable to encounter the competition of the homogenous brands. When the product sales encounter bottleneck, it is necessary to learn "One Stable, Second Find, and Third Change"."One Stable" means that it is inevitable to encounter the Winter Period during the sales process. It is necessary to learn to stabilize the team mentality during the cold winter period. "Second Find", after stabilizing the mentality, the product iterative update and the community analysis should be carried out through finding the defects of the product and the sales bottleneck. "Third Change", it is necessary to change the trial and error with a small amount after finding out where the problem is. Because the enterprise is like a big fishing boat, the selling products is just like fishing in the sea, and the swimming of the fish is just like the constantly changing needs of people. Therefore, in the process of enterprise growth, it may be necessary to change the direction constantly, but the general direction must be set at the beginning. It must be hard to change the direction of a big fishing boat, but we can try the trial and error with the small Angle. To look for the changing fish group through the change of the small Angle and to explore the most real needs of customers through the lowest cost. This is the method and mentality that every company needs to learn.

The cross-border e-commerce should pay more attention to the development of information technology in the future, and should make full use of big data cloud computing, LBS and other new technologies, and should carry out the data mining to make the right marketing strategy in order to 
evaluate the forecast. In the future, advances in technology will allow electricians and consumers to enjoy the best shopping experience.

\section{Acknowledgements}

In this paper, the research was sponsored by the 2017 Undergraduate Students' Innovative Training Project (National level) of Education Department of Guangdong Province of China(20170408), Foshan Science and Technology Bureau Project(2016AG100382), and Foshan Science and Technology Innovation Project(2016AG100792).

\section{References}

[1]Yu KeBai. China's imports of cross-border electricity business status, problems and related recommendations [D]. Shanghai Jiaotong University, 2015.4-5

[2]Chen xia. Brief discussion on the development trend and countermeasures of cross-border e-commerce in China [J]. Management and technology of small and medium-sized enterprises (middle 10), 2017.(05)35-36.

[3] Liwan District of Guangzhou City Longxi Yuxin electronics factory. Mobile fast charge the evaluation, 2016.1-2

[4]Wei Feiqiong. Development Strategy of cross-border electricity under strategic dividend of one belt one road [A]. Renmin University of China, 2017.18-23

[5]China Report Hall. 2013 - 2018 Smartphone User Growth Forecast, 2013.1-2

[6]Chen Huan. Analysis of cross-border electric business enterprises independent brand marketing strategy [A] .Nanchang University, 2015. 7-8 